\title{
SNOWPACK RECONSTRUCTIONS INCORPORATING CLIMATE IN THE UPPER GREEN RIVER BASIN (WYOMING)
}

\author{
SALLYROSE ANDERSON ${ }^{1 *}$, CODY L. MOSER ${ }^{1}$, GLENN A. TOOTLE ${ }^{1}$, HENRI D. GRISSINO-MAYER ${ }^{2}$, \\ JANAK TIMILSENA ${ }^{3}$, and THOMAS PIECHOTA ${ }^{4}$ \\ ${ }^{1}$ University of Tennessee, Department of Civil and Environmental Engineering, 67 Perkins Hall, Knoxville, TN 37996 USA \\ ${ }^{2}$ Laboratory of Tree-Ring Science, University of Tennessee, Department of Geography, Knoxville, \\ TN 37996 USA \\ ${ }^{3}$ Idaho Power Company, Boise, ID 83707 USA \\ ${ }^{4}$ University of Nevada, Las Vegas, Office of Sustainability and Multidisciplinary Research, Las Vegas, NV 89054 USA
}

\begin{abstract}
The Green River is the largest tributary of the Colorado River. Given that snowpack is the primary driver of streamflow, information on the long-term regional snowpack (regionalized April 1 Snow Water Equivalent (SWE)) variability would provide useful information for water managers and planners. Previous research efforts were unable to develop skillful SWE reconstructions using tree-ring chronologies in the Upper Green River Basin (UGRB) of Wyoming because of limited tree-ring chronologies in the area. The current research uses Principal Components Analysis to regionalize April 1 snowpack data in the UGRB. Recent research efforts developed six new tree-ring chronologies in and adjacent to the UGRB. These new chronologies, along with 38 existing chronologies, were correlated with the regionalized SWE data. Chronologies positively correlated at a $95 \%$ confidence level or higher were retained. Stepwise linear regressions were performed and a reconstruction of UGRB regional April $1 \mathrm{SWE}$ was achieved $\left(\mathrm{R}^{2}=0.21\right)$. Climate signals (Pacific Decadal Oscillation (PDO) and Southern Oscillation Index (SOI)) were introduced to the predictor variables and an additional regression was performed. Inclusion of the SOI resulted in a statistically skillful reconstruction $\left(\mathrm{R}^{2}=\right.$ 0.58). Temporal drought periods for SWE and for streamflow were examined for the UGRB and a direct relationship was observed.
\end{abstract}

Keywords: dendrochronology, snowpack reconstruction, Southern Oscillation, tree rings, Upper Green River Basin.

\section{INTRODUCTION}

The Green River, which runs through Wyoming and Utah, is the largest tributary to the Colorado River in the Upper Colorado River Basin (UCRB). The accumulation and springsummer melt of snowpack in the Upper Green River Basin (UGRB) is the primary driver of streamflow in the Green River. The UGRB is bounded by the Wyoming Range to the west, the Gros Ventre Range to the north, and the Wind River Range to the east. The UGRB headwaters were first studied as part of the Lake Powell Research Project (Stockton and Jacoby 1976), in

*Corresponding author: sallyrose.anderson@gmail.com which tree-ring data were used to examine longterm variability in streamflow by reconstructing headwater gage records and main-stem river gage records. In the 1976 report, two headwaters gage reconstructions were completed for the Green River at Warren Bridge, WY and New Fork River, WY.

Recent research has attempted to update and improve the results obtained by Stockton and Jacoby (1976). Two projects directed at new and/ or improved streamflow reconstructions included Timilsena et al. (2007) and Woodhouse et al. (2006). Timilsena et al. (2007) attempted reconstructions at three gage locations in the UGRB in Wyoming. These sites were located near the city of Green River (WY), at the Green River at Warren 
Bridge, and at the East Fork River near Big Sandy. For the Green River at Warren Bridge and the East Fork River near Big Sandy, Timilsena et al. (2007) determined that an insufficient number of predictors (i.e. tree-ring chronologies) were available for the reconstruction regression model. For the Green River near Green River (WY), they obtained an $\mathrm{R}^{2}$ value of 0.40 and, again, attributed this to a lack of tree-ring chronologies in the region.

Woodhouse et al. (2006) likewise developed a reconstruction for the Green River near the Green River streamflow station. This reconstruction did show a slightly higher amount of overall streamflow variance explained $\left(\mathrm{R}^{2}=0.48\right)$ when compared to Timilsena et al. (2007), but the study also raised concerns regarding the heavy reliance on tree-ring chronologies from northern Colorado and Utah because few updated chronologies were available in southwest Wyoming. Recently, six new tree-ring chronologies were developed (Watson et al. 2009) in and adjacent to the UGRB. This resulted in successful reconstructions of nine streamflow gages in the UGRB (Barnett et al. 2010), including the improvement in explained variance of the Green River near Green River station $\left(\mathrm{R}^{2}=0.60\right)$.

Few snowpack reconstruction studies have been conducted in the UCRB. Woodhouse (2003) focused on the Gunnison River basin region in western Colorado. The variance explained by the reconstruction was $63 \%$ and the reconstruction extended back 431 years. The study determined that variability in the Twentieth Century represented the long-term record for the region's general characteristics (mean, standard deviation). The Twentieth Century, however, lacked extreme events that occurred in the first half of the 431year reconstruction (Woodhouse 2003). Timilsena and Piechota (2008) regionalized and reconstructed Snow Water Equivalent (SWE) for the UCRB. The study regionalized 39 snow course stations into four distinct regions in the UCRB (Region 1Eastern, Region 2-Western, Region 3-Southern, and Region 4-Northern). The variance explained by the 480-year reconstructions was $61 \%$ for Region 1, 44\% for Region 2, and 58\% for Region 3 (Timilsena and Piechota 2008). Region 4, which spatially coincides with the UGRB, was eliminated from the reconstruction because it had limited correlation with the tree-ring chronologies and none of the chronologies were suitable for use in a regional reconstruction (Timilsena and Piechota 2008). Given that incorporation of the six new treering chronologies (Watson et al. 2009) resulted in the successful reconstruction of nine headwaters in the UGRB (Barnett et al. 2010), we hypothesized that the incorporation of these chronologies would increase the ability of successfully reconstructing snowpack in Region 4 (UGRB).

Graumlich et al. (2003) presented a unique approach in which Pacific Ocean climate variability (specifically the El Niño-Southern Oscillation (ENSO) and the Pacific Decadal Oscillation (PDO)) were used in developing streamflow reconstructions for the Yellowstone River. Tree-ring chronology data were supplemented with reconstructed indices that represented ENSO and PDO. Initially, a simple regression model was developed using local tree-ring chronologies that yielded a regression that explained $42 \%$ of streamflow variation. Next, ENSO and PDO indices were incorporated into a new model that resulted in an improved regression capable of explaining $52 \%$ of streamflow variation. Given the close proximity of the Yellowstone River to the UGRB and the establishment of ENSO and PDO signals in UGRB snowpack (McCabe and Dettinger 2002; Hunter et al. 2006; Aziz et al. 2010), we hypothesized that incorporation of these climate signals would further improve the statistical skill of a snowpack reconstruction in the UGRB.

The objective of the current research is to produce the first skillful reconstruction of UGRB snowpack. The novel approach of the incorporation of Pacific Ocean climate variability in the form of ENSO and PDO builds on previous research efforts in the region and may result in the successful reconstruction of regional snowpack. Following the reconstruction of regional snowpack, the data will be analyzed for information regarding drought duration and drought potential, as compared to data available from regional streamflow gages.

\section{DATA AND METHODS}

\section{Snowpack Data and Regionalization}

In the study by Timilsena and Piechota (2008), snow course data were collected from 


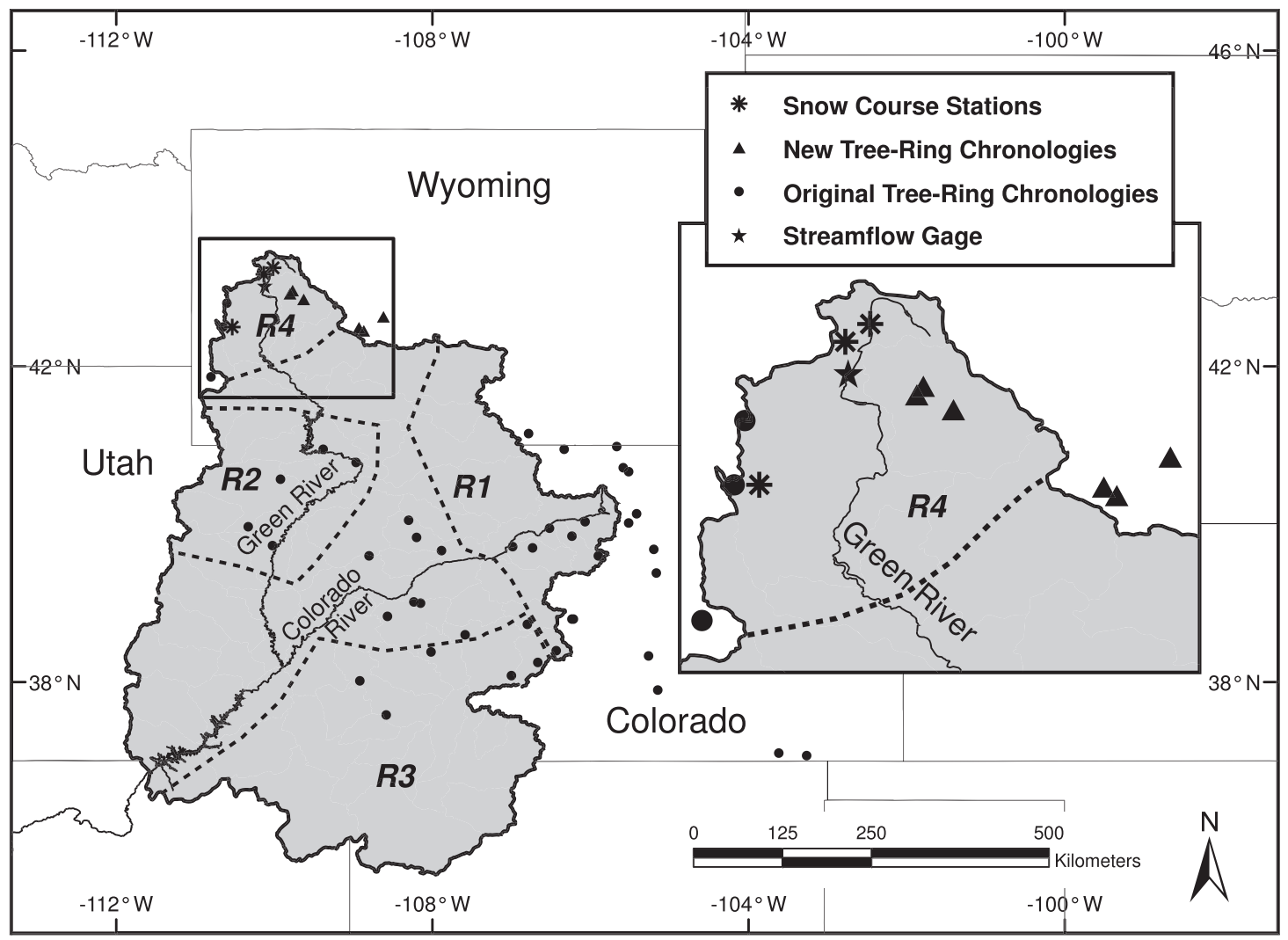

Figure 1. Map illustrating the location of applicable snow course stations, new and previously utilized tree-ring chronologies, the streamflow gage, and the four regions identified by Timilsena and Piechota (2008).

the United States Department of Agriculture (USDA), Natural Resources Conservation Service (NRCS) website (http://www.wcc.nrcs.usda.gov/ snowcourse/). Varimax rotated Principal Components Analysis (PCA) was applied to 39 snow course stations in the UCRB, which resulted in four snowpack regions (Figure 1) being identified (Timilsena and Piechota 2008). Snow course data for Region 4 from 1940 to 1980 were obtained from Timilsena and Piechota (2008) and consist of the yearly average of April 1 Snow Water Equivalent for the three individual snow course stations identified in Region 4 (Table 1).

\section{Residual Tree-Ring Chronologies and Pre-Screening with Regional Snowpack}

Timilsena and Piechota (2008) obtained treering data from the International Tree-Ring Data Bank (ITRDB) (Grissino-Mayer and Fritts 1997) website maintained by the National Oceanic and Atmospheric Administration (NOAA), World Data Center for Paleoclimatology (http://www. ncdc.noaa.gov/paleo/treering.html) and from recent hydrologic studies (Gray et al. 2004). The available data include recent chronologies for the basin as described in Woodhouse et al. (2006). Forty-four residual chronologies in the vicinity of

Table 1. Location data and period of record for the three snow course stations.

\begin{tabular}{lcccc}
\hline \multicolumn{1}{c}{ Station } & State & Latitude & Longitude & Period of Record \\
\hline Snider Basin & WY & 42.50 & -110.53 & $1937-2009$ \\
Kendall & WY & 43.25 & -110.02 & $1938-2009$ \\
Loomis Park & WY & 43.17 & -110.13 & $1939-2009$ \\
\hline
\end{tabular}


the UCRB were identified for the original Timilsena and Piechota (2008) study. Watson et al. (2009) developed six new tree-ring chronologies in and adjacent to the UGRB. These six chronologies were added to the 44 chronologies from the previous study, resulting in a total predictor pool of 50 chronologies (Figure 1, Table 2).

The residual tree-ring chronologies for the year of growth $(y)$, the previous year $(y-1)$, and the subsequent year $(y+1)$ were included in the regression models (Fritts 1976; Fritts et al. 1979; Graumlich et al. 2003; Timilsena and Piechota 2008). Correlations between Region 4 April 1 SWE and the 50 residual tree-ring chronologies for the overlapping period of 41 years (1940-1980) were used to determine which data sets would be used as initial predictors in stepwise linear regression (SLR) to develop reconstructions of Region 4 April $1^{\text {st }}$ SWE. The residual tree-ring chronologies were correlated to Region 4 April 1 SWE such that residual tree-ring chronologies with positive correlations ( $\mathrm{p} \leq 0.05$ ) were retained (Timilsena and Piechota 2008). Stability analysis, which included performing a 25 -year moving correlation window between tree-ring chronologies and SWE, was used to identify reliable tree-ring chronologies and confirm that no significant changes occurred between tree-growth and climate variables during the period of overlapping record that might be caused by overriding natural causes (e.g. wildfires, insects, and lightning) (Biondi and Waikul 2004).

\section{Pacific Ocean Climate (Southern Oscillation and Pacific Decadal Oscillation)}

Similar to Graumlich et al. (2003), this study used the reconstructed Southern Oscillation Index (SOI) created by Stahle et al. (1998). This data set was obtained from the National Climatic Data Center (NCDC) and the National Oceanic and Atmospheric Administration (NOAA) Climate Reconstructions website (ftp://ftp.ncdc.noaa.gov/ pub/data/paleo/treering/reconstructions/soi_recon. txt). This index consisted of winter season (December, January, February) SOI from 1706 to 1977. This study used a reconstructed Pacific Decadal Oscillation (PDO) created by D'Arrigo et al. (2001). This data set was also obtained from the
NCDC and NOAA Climate Reconstruction website (ftp://ftp.ncdc.noaa.gov/pub/data/paleo/treering/ reconstructions/pdo-darrigo2001.txt). It consisted of an annual record from 1700 to 1979. The winter SOI (December of the previous year, January and February of the current year) and the previous year average PDO index were used in the regression models.

\section{Regression Model (Stepwise Linear Regression)}

Initially, residual tree-ring chronologies that passed pre-screening were entered as predictors into the SLR model, and validation statistics were determined. Next, the Southern Oscillation Index (SOI) and the Pacific Decadal Oscillation (PDO) index were entered into the model as predictors along with the residual tree-ring chronologies, and validation statistics were calculated.

SLR is a widely accepted method used in climate reconstructions (Barnett et al. 2010; Woodhouse 2003; Watson et al. 2009). SLR uses a forward selection, backward elimination approach. Following Woodhouse et al. (2006), parameters were set with an alpha-to-enter value of 0.05 and an alpha-to-remove value of 0.10 . First, the stepwise regression model entered predictors (residual tree-ring chronologies, SOI, PDO) and selected, or retained, the predictors that were statistically significant as determined by a threshold alpha value (0.05). After the stepwise regression model selected the forward selection predictors, backward elimination was performed. A threshold alpha value $(0.10)$ determined which predictors were not statistically significant and were not retained in the model. This forward and backward stepping through the predictors continued until the model had selected the predictors that were the most statistically significant.

\section{Drought Analysis}

Reconstructed and observed SWE data were examined for drought conditions. Similar to Timilsena and Piechota (2008), a drought event was defined as a standardized yearly SWE value of less than the mean (zero, from standardization). The duration of the drought was defined as the 
Table 2. Location data, start year information, and species classification for the tree-ring chronologies.

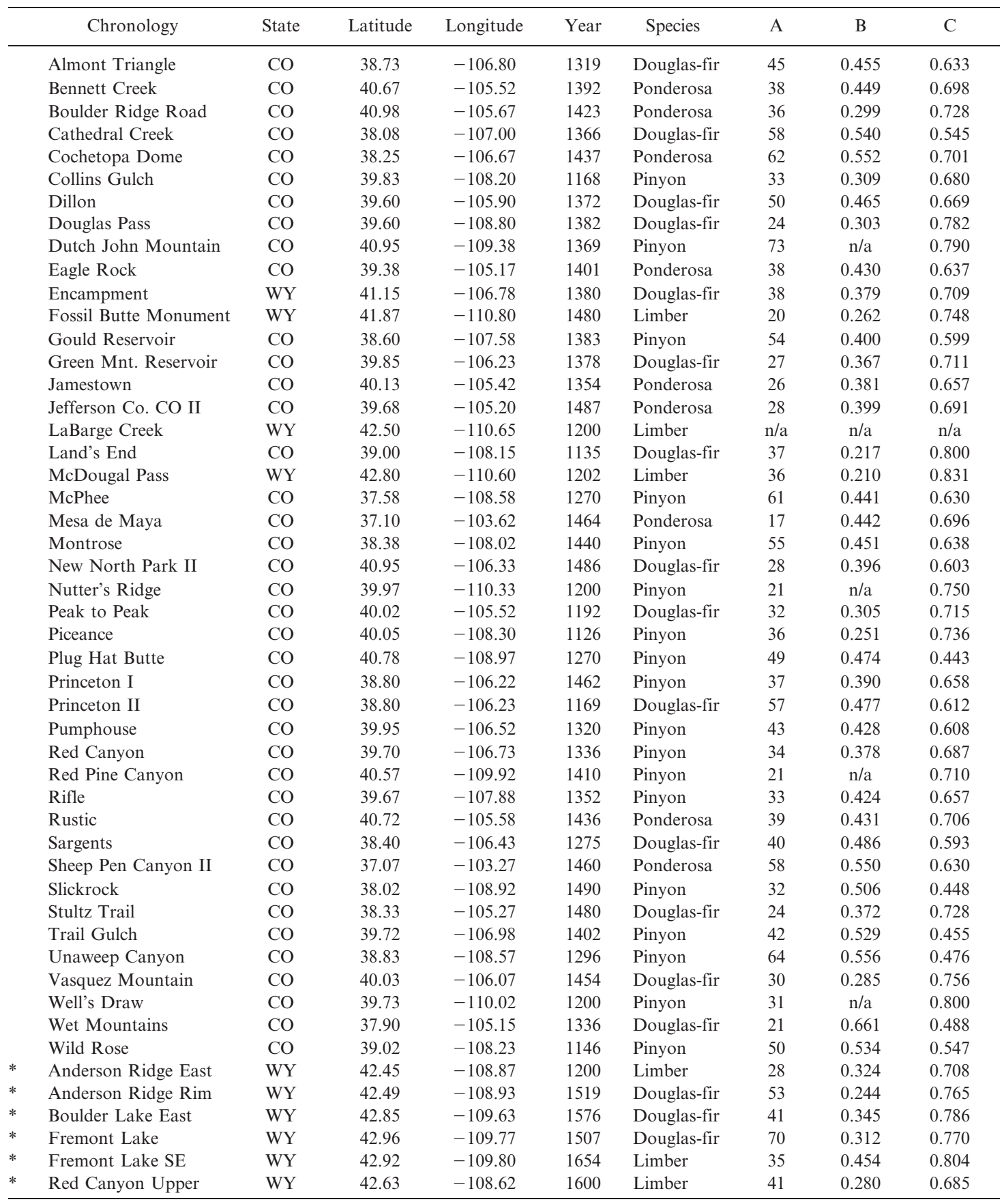

A: Number of Dated Series.

B: Average Mean Sensitivity.

C: Average Autocorrelation.

$\mathbf{n} / \mathbf{a}$ indicates a value that is not publicly available.

* indicates a tree-ring chronology that was not used by Timilsena and Piechota (2008) and was developed by Watson et al. (2009). 
Table 3. Validation statistics used for determining statistical skill and model accuracy for the model using only tree-ring chronologies and for the model using tree-ring chronologies and the Southern Oscillation Index (SOI).

\begin{tabular}{lcccccc}
\hline \multicolumn{1}{c}{ Model } & Calibration Period & $\mathrm{R}^{2}$ & Predicted $\mathrm{R}^{2}$ & Sign Test (Hit/Miss) & D-W & RMSE \\
\hline TRCs & $1940-1980$ & 0.21 & 0.14 & $26 / 15$ & 2.15 & 0.88 \\
TRCs + SOI & $1940-1977$ & 0.58 & 0.50 & $32 / 6$ & 1.86 & 0.66 \\
\hline
\end{tabular}

number of consecutive years that the standardized April $1^{\text {st }}$ SWE was less than the mean.

Drought duration based on SWE was also compared with drought duration based on data from unimpaired water-year streamflow stations. A 385-year record of reconstructed streamflow data for the Green River at Warren Bridge, near Daniel, WY was obtained from Barnett et al. (2010). These data were combined with observed streamflow data for this gage station. Similar to the SWE data, a drought event was defined as a series of consecutive years that the water-year streamflow values were less than the mean. Drought duration was defined as the number of consecutive years that the water-year streamflow was less than the mean. Per Timilsena and Piechota (2008), drought duration was examined for 3-, 5-, and 10-year moving averages.

\section{RESULTS}

\section{Snow Course Stations}

Per Timilsena and Piechota (2008), varimax rotated PCA was performed to confirm the existence of the snowpack region. The three snow course stations in that region were identified as the leading principal component. A regional April 1 SWE value was created by normalizing data from these three stations to a mean of zero and standard deviation of one (Timilsena and Piechota 2008).

\section{Tree-Ring Chronologies}

During pre-screening, all of the tree-ring chronologies originally selected by Timilsena and Piechota (2008) were eliminated from the model, substantiating the claims made in their paper. The six new tree-ring chronologies developed by Watson et al. (2009) underwent the same pre-screening criteria. One of these chronologies was found to be both stable and highly correlated (95\%) with regional April 1 SWE. None of the lagged chronologies $(y-1, y+1)$ passed pre-screening. The chronology that passed prescreening is located at Fremont Lake (Table 2).

\section{SWE Reconstructions}

Two regression models were developed to obtain the SWE reconstruction with the highest level of explained variance. Both regression models used the Fremont Lake tree-ring chronology developed by Watson et al. (2009). The first model used a period of record of 1940-1980 for calibration, per Timilsena and Piechota (2008). This model retained the Fremont Lake chronology and explained $21 \%$ of the variance in SWE records. The second model incorporated the reconstructed SOI data from Stahle et al. (1998) and the reconstructed PDO data from D'Arrigo et al. (2001). To include the SOI, the period of record for calibration was reduced by three years. The period still began in 1940, but the ending year was reduced from 1980 to 1977 given the fact that the reconstructed SOI data end in 1977. In this model (Table 3), the Fremont Lake chronology and the

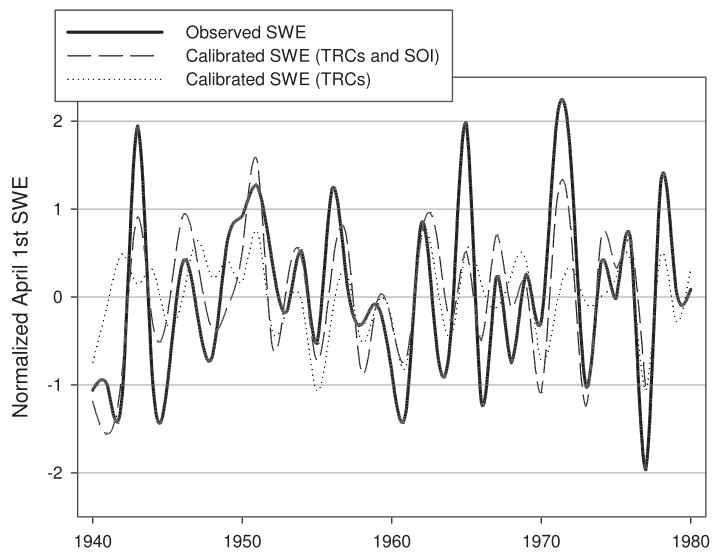

Figure 2. Graphical representation of the calibration period for the two models alongside the observed record for this period. 

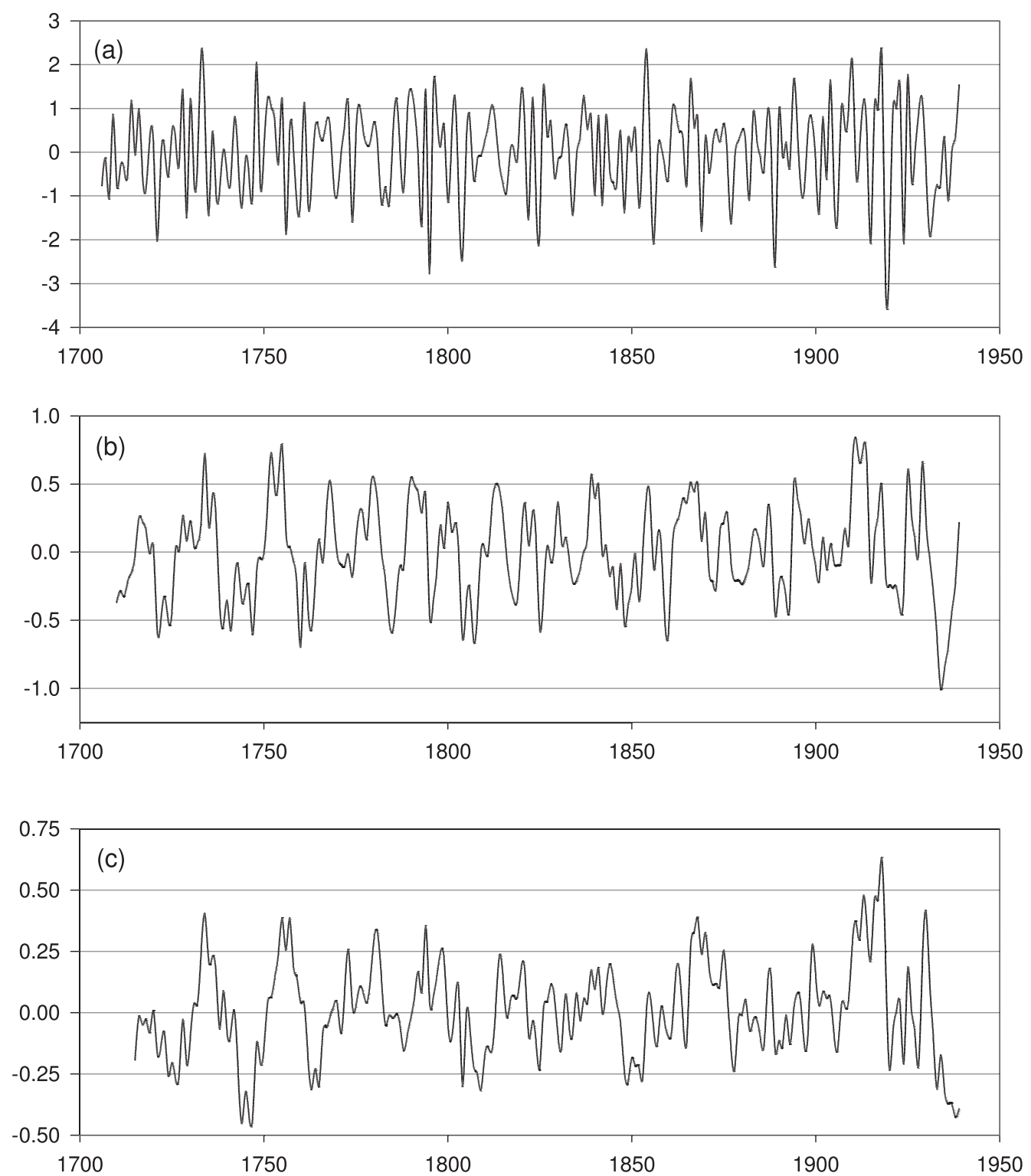

Figure 3. Graphical representation of the reconstructed normalized April $1^{\text {st }}$ SWE, showing deviation from the mean (0.00): (a) Reconstructed annual values, (b) Reconstructed values using a 5-year moving average (end-year), (c) Reconstructed values using a 10 -year moving average (end-year).

SOI were retained but the PDO was rejected. This model provided an $\mathrm{R}^{2}$ value of 0.58 .

The validation statistics for the regression model involving tree-ring chronologies and climate signals were very strong. The $\mathrm{R}^{2}$ statistics indicated that $58 \%$ of data variation was explained in the model and reconstructed values will explain $50 \%$ of historical variation. This method of leave- one-out cross-validation determines the accuracy of the model for predicting future values by ensuring that the variance explained has not been overestimated by the regression model (Barnett et al. 2010). Sign test results showed that the direction of change between the observed SWE data and the reconstructed SWE matched favorably. The Durbin-Watson statistic revealed very 
Drought Duration

(a)

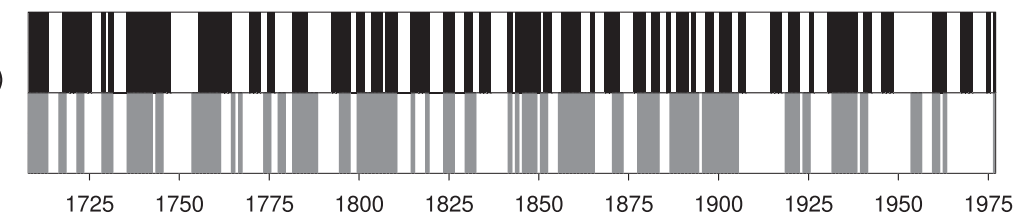

(b)

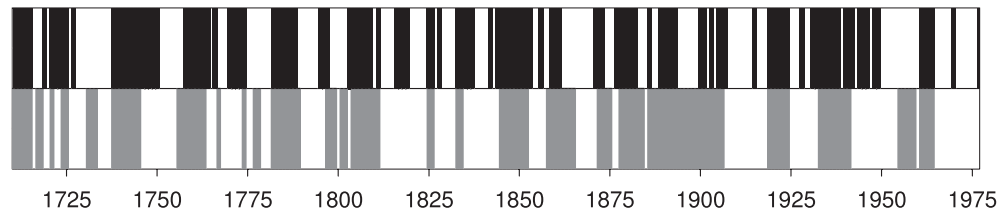

(c)

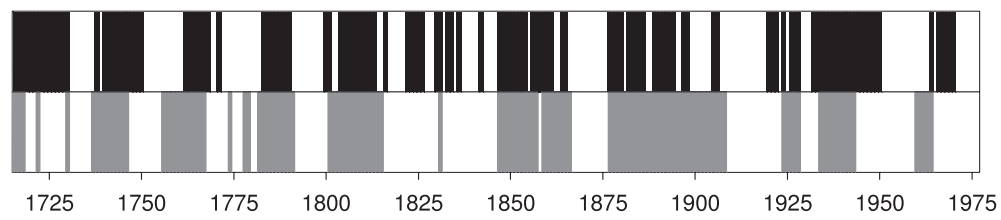

Snow Water Equivalent
Streamflow

Figure 4. Drought duration analysis for the reconstructed period with shaded years indicating a level (SWE or streamflow) below the mean: (a) 3-year moving average, (b) 5-year moving average, (c) 10-year moving average.

little autocorrelation within the predictors included in the model using tree-ring chronologies and the SOI $\left(\mathrm{R}^{2}=0.58\right)$. The low value of the root mean square error (RMSE) value indicated an accurate fit of the model and the lack of variance inflation factor (VIF) verified that the model had not been over fit. Figure 2 shows the calibration period for the two models, along with the observed values for that time period.

The second model, which included the SOI, provides a statistically stronger reconstruction of regional April 1 SWE. This model was used to reconstruct SWE to 1706 (Figure 3). The reconstructed SOI data, which begin in 1706, was the controlling factor for the length of the reconstruction.

\section{Drought Analysis}

The 3-, 5-, and 10-year moving average drought analyses for normalized SWE and for streamflow were compared to analyze the shortand long-term drought potential for the UGRB region. When comparing reconstructed water-year streamflow for the gage at Green River at Warren Bridge, near Daniel, WY (per Barnett et al. 2010) to the reconstructed regional UGRB April 1 SWE (1706 to 1939), deficit snowpack was the primary driver of prolonged drought. The comparison of yearly below-average water-year streamflow revealed that approximately $75 \%$ of the years corresponded to below-average regional April 1 SWE (Figure 4).

For this analysis, the water-year streamflow was standardized (mean of zero, standard deviation of one) for comparison to snowpack. Wateryear drought consistently related to deficit snowpack for the same period (Table 4). The values displayed were the cumulative deficit for the drought period.

\section{DISCUSSION}

Incorporation of the six additional TRCs from Watson et al. (2009) allowed for a reconstruction of the UGRB region that explained $21 \%$ 
Table 4. Comparative cumulative deficit statistics for streamflow and SWE during drought periods.

\begin{tabular}{ccc}
\hline $\begin{array}{c}\text { Drought } \\
\text { Period }\end{array}$ & $\begin{array}{c}\text { Streamflow: } \\
\text { Cumulative Deficit } \\
\text { (Standardized) }\end{array}$ & $\begin{array}{c}\text { SWE: } \\
\text { Cumulative Deficit } \\
\text { (Standardized) }\end{array}$ \\
\hline $1706-1711$ & -3.8 & -2.1 \\
$1735-1740$ & -4.3 & -2.8 \\
$1803-1809$ & -6.6 & -3.1 \\
$1844-1848$ & -4.8 & -2.3 \\
$1931-1935$ & -5.5 & -3.5 \\
\hline
\end{tabular}

of the SWE variance. Although this was an improvement, this was not considered a statistically skillful reconstruction. Inclusion of the SOI from Stahle et al. (1998) resulted in the first statistically skillful reconstruction $\left(\mathrm{R}^{2}=0.58\right)$ of SWE in this region.

Timilsena and Piechota (2008) reconstructed SWE for three of the four regions they identified. These reconstructions explained $44-61 \%$ of the variance. The reconstruction generated in this study for the UGRB with the additional TRCs and the SOI explains $58 \%$ of the variance, indicating that this reconstruction is similar in statistical skill to the results obtained by Timilsena and Piechota (2008). However, the reconstructions generated in Timilsena and Piechota (2008) have a start date of 1500, allowing for a 480-year reconstruction. The SOI data start in 1706, which limited our model, but still allowed for a 271-year reconstruction. It is possible that omission of the SOI data set in favor of a Nino 3.4 data set or an alternate SOI data set may decrease the statistical skill of the reconstruction, but may allow for a longer period.

Examination of the drought statistics shows the relationship between snowpack deficit and streamflow deficit. Given the strong relationship between snowpack drought years and streamflow drought years, the magnitude of spring snowpack can be used to predict the severity of a potential drought. This information is critical for decisions regarding water supply for the UGRB and UCRB regions. An understanding of historic highs and lows with regard to water availability will help water planners understand the potential extreme conditions possible in the region. If the severity of a drought can be determined at the beginning of the summer, necessary precautions can be taken to conserve available water for later months, potentially thwarting the economic and political pressures associated with water shortages.

\section{Future Work}

Future work will include additional SWE data from snow telemetry (SNOTEL) stations in addition to snow course stations. Using SNOTEL data may improve the statistical skill of the reconstruction models. Given the success seen when incorporating climate signals (SOI) in Region 4, reconstructions could be reexamined in Regions 1, 2 , and 3 , this time including climate signals. Furthermore, investigation into the specific Pacific Ocean sea-surface temperatures that are driving UCRB snowpack, similar to Aziz et al. (2010), may result in identification of a new climatic region that positively impacts the statistical skill of the reconstructions.

\section{ACKNOWLEDGMENTS}

The research is supported by the National Science Foundation P2C2 award AGS-1003393.

\section{REFERENCES CITED}

Aziz, O. A., G. A. Tootle, S. T. Gray, and T. C. Piechota, 2010. Identification of Pacific Ocean sea surface temperature influences of Upper Colorado River Basin snowpack. Water Resources Research 46:W07536. doi:10.1029/2009WR008053.

Barnett, F. A., S. Gray, and G. Tootle, 2010. Upper Green River Basin (United States) streamflow reconstructions. American Society of Civil Engineers Journal of Hydrologic Engineering 15(7):567-579.

Biondi, F., and K. Waikul, 2004. DENDROCLIM2002: a C++ program for statistical calibration of climate signals in treering chronologies. Computers and Geosciences 30(3):303-311.

D'Arrigo, R., R. Villalba, and G. Wiles, 2001. Tree-ring estimates of Pacific decadal climate variability. Climate Dynamics 18(3-4):219-224.

Fritts, H. C., 1976. Tree Rings and Climate. Academic Press, London and New York; $567 \mathrm{pp.}$

Fritts, H. C., G. R. Lofgren, and G. A. Gordon, 1979. Variations in climate since 1602 as reconstructed from treerings. Quaternary Research 12(1):18-46.

Graumlich, L., M. Pisaric, L. Waggoner, J. Littell, and J. King, 2003. Upper Yellowstone river flow and teleconnections with Pacific basin climate variability during the past three centuries. Climatic Change 59:245-262. 
Gray, S. T., S. T. Jackson, and J. L. Betancourt, 2004. Tree-ring based reconstructions of interannual to decadal-scale precipitation variability for northeastern Utah. Journal of the American Water Resources Association 40:947-960.

Grissino-Mayer, H. D., and H. C. Fritts, 1997. The International Tree-Ring Data Bank: Growth and Adaptation to the World Community. Final Report, Paleoclimatology Program, National Oceanic and Atmospheric Administration, Boulder, Colorado; $61 \mathrm{pp}$.

Hunter, T., G. Tootle, and T. Piechota, 2006. Oceanicatmospheric variability and western US snowfall. Geophysical Research Letters 33:L13706, doi:10.1029/2006GL026600.

McCabe, G. J., and M. D. Dettinger, 2002. Primary modes and predictability of year-to-year snowpack variations in the western United States from teleconnections with Pacific Ocean climate. Journal of Hydrometeorology 3:13-25.

Stahle, D. W., R. D. D’Arrigo, P. J. Krusic, M. K. Cleaveland, E. R. Cook, R. J. Allan, J. E. Cole, R. B. Dunbar, M. D. Therrell, D. A. Gay, M. D. Moore, M. A. Stokes, B. T. Burns, J. Villanueva-Diaz, and L. G. Thompson, 1998. Experimental dendroclimatic reconstruction of the Southern Oscillation. Bulletin of the American Meteorological Society 79:2137-2152.
Stockton, C. W., and G. C. Jacoby, 1976. Long-term SurfaceWater Supply and Streamflow Trends in the Upper Colorado River Basin Based on Tree-ring Analyses. Lake Powell Research Project Bulletin 18, 70 pp.

Timilsena, J., and T. C. Piechota, 2008. Regionalization and reconstruction of snow water equivalent in the upper Colorado River Basin. Journal of Hydrology 352:94-106.

Timilsena, J., T. C. Piechota, H. G. Hidalgo, and G. Tootle, 2007. Five hundred years of drought in the upper Colorado River Basin. Journal of the American Water Resources Association 43(3):798-812.

Watson, T., F. A. Barnett, S. Gray, and G. Tootle, 2009. Reconstructed streamflow for the headwaters of the Wind River, Wyoming USA. Journal of the American Water Resources Association 45(1):1-13.

Woodhouse, C. A., 2003. A 431-yr reconstruction of western Colorado snowpack from tree-rings. Journal of Climate 16: 1551-1561.

Woodhouse, C. A., S. T. Gray, and D. M. Meko, 2006. Updated stream flow reconstructions for the upper Colorado River basin. Water Resources Research 42:W05415.

Received 15 June 2011; accepted 1 February 2012. 